Allpanchis, año XLVII, núm. 86. Arequipa, julio-diciembre de 2020, pp. 165-204.

ISSN impreso 0252-8835 / ISSN en línea 2708-8960

DOI: https://doi.org/10.36901/allpanchis.v47i86.1175

artículos académicos

\title{
La memoria andina colonial: escritores indígenas y mestizos de los siglos XVI y XVII
}

\author{
Alejandro Herrera Villagra \\ Universidad Nacional de San Antonio Abad (Cusco, Perú) \\ alehv772@hotmail.com \\ Código ORCID: 0000-0002-5254-7919 \\ A mi madre, Rosa Esther Villagra
}

\section{RESUMEN}

Tres excelentes escritores, el Inca Garcilaso de la Vega, Juan de Santa Cruz Pachacuti Yamqui Salcamaygua y Felipe Guaman Poma de Ayala, consiguieron registrar un recuerdo trascendente de la antigüedad andina. Postulamos que en los Comentarios Reales [1609], la Relación de Antigüedades deste Reyno del Pirú [1613] y la Nueva Corónica y Buen Gobierno [1615], ellos construyeron una memoria del pasado reivindicado a pesar de la colonialidad de su época. Este hecho nos ha impulsado a 
interpretar las circunstancias en que la historia de los pueblos de los Andes durante el siglo XVI experimentó una serie de alteraciones culturales, y a explicar cómo una identidad étnica trascendió gracias a la escritura histórica.

Palabras clave: Andes Coloniales, cultura, escritura, memoria, identidad Colonial Andean Memory: Indigenous and mestizo writers of the 16th
and 17th centuries

\begin{abstract}
Three excellent writers, Garcilaso de la Vega, Juan de Santa Cruz Pachacuti Yamqui and Felipe Guaman Poma, managed to register a transcendent remembrance of andean antiquity. We postulate that in the Comentarios Reales de los Incas (Royal Comments of the Incas) [1609], the Relación de Antigïedades deste Reyno del Pirú (Relation of Antiques in this Realm of Peru) [1613], and the Nueva Corónica y Buen Gobierno (New Chronicle and Good Government) [1615], they built a memory of the past claimed in spite of the coloniality of its time. This fact has prompted us to interpret the circumstances in which the history and culture of the peoples of the Andes during the XVI century underwent a series of transformations and to explain how an ethnic identity transcended through the historic writings.
\end{abstract}

KEYworDs: Colonial Andes, culture, writing, memory, identity 
Nukñu wach'eq ñawillaykita/ Kicharimuy, Ancha qokoq makillaykita/ Mast'arimuy Chay samiwan kallpanchasqata/ Ripuy niway. ANÓNIMO $^{1}$

\section{INTRODUCCIÓN}

LA MEMORIA OCUPA UN ESPACIO fundamental en el estudio moderno de la historia y la cultura de la humanidad debido a la necesidad trascendental de los pueblos de recordar, construir y registrar un recuerdo sobre sí mismos. La propia UNESCO está innovando con su programa internacional denominado Memoria del Mundo, ${ }^{2}$ poniendo en valor piezas históricas y culturales como bagaje común de todos los países del mundo (textos, complejos de arqueología, derechos humanos). Las obras que aquí se comentan deberán ser parte de esta memoria mundial en un futuro no lejano, dado que en el caso del Cusco ya se ha propuesto que los Comentarios Reales de los Incas, por ejemplo, sea patrimonio mundial en la Memoria del Mundo, lo que da pie para pensar que otros textos importantes también debieran correr este mismo destino. La memoria humana es por derecho natural una faceta innegable de las ciencias históricas. Nuestro análisis comienza valorando la documentación colonial realizada por escritores indígenas o mestizos y continúa con el hecho cultural que comienza con el fenómeno de la memoria, identidad y cultura que estos actores de la historia colonial encarnaron. Incluiremos, además, algunas fuentes españolas para fundamentar elementos indispensables de esta propuesta. En este trabajo, resumen de nuestra tesis doctoral (Herrera Villagra 2016) nos interesa analizar la obra de

1 «Condesciende a abrir tus ojos/ que irradian claridad/ Extiéndenos/tus manos generosas/ Y con esa buena seña alentados/dinos: jregresen!». Versión de Odi González (Anónimo 2014: 33).

2 <http://www.unesco.org/new/es/communication-and-information/memoryof-the-world/register/ $>$. 
individuos andinos de los siglos XVI y XVII afectados por densos problemas políticos, religiosos y culturales. ${ }^{3}$ Sin duda, el problema se traduce en hegemonías que intentaban controlar a los sujetos subalternos: ello generó cambios en el ethos y praxis de los grupos en interacción. Pero, si bien los grupos étnicos colonizados fueron oficialmente controlados por el poder español, existió un espacio mental que no logró ser reducido: es el espacio individual cognitivo que funcionó subjetivamente y que con el tiempo logró producir cohesión temática, una especie de recolección de lo que quedó diseminado, aun expresado en un plano clandestino o marginal, el del camuflaje o la adaptación. Esta idea se articula con la hipótesis de la persistencia secular de la cultura andina colonizada que se verifica en la historia de la relación entre el Imperio español y el Tahuantinsuyo. En estos campos conflictivos es donde insertamos nuestra reflexión. ${ }^{4}$

Pues bien, ¿qué es la memoria andina y qué representa? ¿Cómo contemplarla, reconstituirla, cómo entender su funcionamiento general? ¿Qué quedó de la vieja tradición en el pensamiento de los andinos que pasaron a ser sujetos colonizados por una sociedad foránea? ¿Podemos construir un concepto operativo de aquella me-

3 No siendo quechua-hablantes empleamos la norma básica del quechua castellanizado. Sin ningún interés en polemizar cuestiones de quechuología, no estamos en la penumbra desde que intentamos entender la evolución del quechua en los siglos coloniales (Herrera Villagra 2017). Por ahora, no obstante, nos interesa solamente el problema etnohistórico. Sobre el bilingüismo histórico, véase la obra editada por Escobar, Matos Mar y Alberti (1975). Acerca del contacto inicial entre el quechua y el castellano, hemos consultado Torero (2005; 2007), Cerrón Palomino (1987; 2010), Parker (2013) e Itier (2015).

4 El tema de la memoria es parte constituyente de nuestra modernidad desde los trabajos de Maurice Halbwachs (2004a; 2004b). Desde entonces el enfoque de la memoria ha ido aunando partidarios, aclarando los imaginarios humanos y aplicándose en diferentes áreas de estudio. Lacan (1982), Yates (2006), Nora (2009), Ricoeur (2008), Gruzinski (2013), entre otros, han utilizado este enfoque para proyectar el estudio de «lo simbólico, lo imaginario y lo real» (Lacan 1982). En particular, los imaginarios, las ideologías y las identidades también aparecen enlazados en la producción teórica del último tiempo en estudios acerca del psicoanálisis, la arqueología o la etnohistoria (Kaulicke 2016; Derrida 1998). 
moria histórica andina? ¿Cuáles son las cualidades que la constituyeron? ¿Son la memoria y la identidad elementos vinculados que definen la reproducción de lo que un pueblo considera una tradición? ¿Hasta qué punto la posibilidad de una memoria andina pudo mantener una identidad bajo el régimen colonial? ${ }^{5}$

La historia de los Andes es ciertamente antiquísima. En todo el campo arqueológico y antropológico de la evidencia es donde visualizamos la existencia de una memoria de los pueblos andinos. Es plausible pensar que el pensamiento antiguo consiguió, a lo largo de miles de años, reproducir el saber y la tradición mediante el uso de signos lingüísticos gráficos o visuales practicados en varios soportes físicos, hecho determinante para el desarrollo de las sociedades andinas complejas. Esas formas del pensamiento pueden estudiarse comprendiendo dos asuntos trascendentes: 1) el sistema de signos que pudo haberse utilizado en la medida en que las necesidades comunicativas fueron satisfechas a través del desarrollo de sistemas auditivos, materiales o visuales que acompañaban a los discursos verbales de los hablantes, y 2) la complejidad inherente de las lenguas nativas antiguas, como el quechua, puquina o moche. Este desarrollo es milenario, pero puede acotarse en este artículo. En rigor proviene de la época de las pinturas rupestres del Período Arcaico, se prolonga por el Horizonte Formativo y Medio y prosigue hasta la Época Incaica que tuvo su propio modelo de comunicación y el más complejo de todos los que presumiblemente existieron en el Horizonte Tardío. Nada sorprendente si consideramos comparativamente la evolución del régimen hegemó-

5 El problema de la escritura indígena no es nuevo. Proviene del siglo XIX y se extiende por el XX. Ibarra Grasso (1953), con una intuición ejemplar, lo abordó. Hoy en día sigue hablándose de una escritura incaica, concepto que creemos se emplea con demasiado apuro y que más bien obstruye el estudio de la cuestión, ya que nos entrampa en categorías eurocéntricas que impiden examinar la otredad cultural en su propio estatuto (cf. Silverman 2014: 157-159). Sobre los quipus, como índice de registro mnemotécnico cualitativo (o sea, narrativo), véase Urton (2016). No desechamos el proyecto de conocer y comprender algún día el sistema de signos andino. Lo que nos preocupa es emplear apropiadas herramientas interpretativas para entender su carácter y singularidad. 
nico del sistema alfabético de escritura que utilizaron los españoles en Europa, heredado a su vez de la cultura de la Antigüedad grecorromana. Respecto de nuestro tema de estudio, debemos indicar que se trata de toda una genealogía tecnológica comunicativa en evolución que podemos rastrear históricamente en el tiempo observando sus diversas fases y etapas en los horizontes continuos ya aludidos. Pensamos, por lo tanto, que los antiguos andinos sintetizaron inteligentemente todos los adelantos previos creando un sistema comunicativo integral a la altura del desafío del Tahuantinsuyo.

El siglo XVI representa un silenciamiento de la cultura andina debido a la imposición de tradiciones y costumbres europeas a través de la ideología cristiana, la evangelización de los indígenas y el decisivo factor del descenso demográfico de la población andina (Estenssoro 2003; Alaperrine-Bouyer 2007; Cook 2010). Es en el ámbito comunicativo donde se registró un cambio cualitativo esencial en los espacios mental, ideológico y tecnológico: el uso oficial de la literatura histórica (cultura del libro, educación), jurídica y teológica, y la imposición de la escritura como principal medio de comunicación entre los actores, la organización social y el poder colonial. En este asunto trascendental hubo una impensada salvedad: la emergencia de una escritura histórica particular en las manos de sujetos andinos que utilizaron este recurso para diferentes actividades y objetivos. Dejando aparte los aspectos formales, ${ }^{6}$ aquí solo nos centraremos en el uso de la literatura histórica que tuvo indudablemente sus propios propósitos. En efecto, a principios del siglo XVII hubo una eclosión sorprendente y determinante: aparecieron obras escritas que rompieron la tradición puramente española de la crónica histórica eurocentrista (Hampe Martínez 1996). Los cronistas Inca Garcilaso, Pachacuti Yamqui y Guaman Poma representan, a nuestro juicio, el desarrollo de una nueva fase de la cultura hispanoamericana que influyó decisivamente en la continuación cultural

6 Véanse Dueñas (2010); Navarro Gala (2015); Lienhard (2016); MacCormack (2016); Lamana (2019). 
de la vida de los pueblos indígenas del Ande, en el que la palabra escrita cobró principal protagonismo en la lucha simbólica que enfrentó a dos culturas que coexistían: la española y la andina.

Los tres autores aludidos y sus obras nos parecen objetos etnohistóricos idóneos para indagar en la naturaleza de sus experiencias vitales y en el contenido de sus obras, doble dificultad que nos acerca al principal problema aquí estudiado: la existencia de una memoria indígena colonial registrada en textos escritos en el sistema alfabético y a través de libros o documentos manuscritos, y sus características más notables como producto de un proceso colonial que afectó la libertad, la lengua y el futuro de quienes vivieron bajo el régimen virreinal en los Andes de los siglos XVI y XVII. El presente artículo ofrece una posibilidad de comprensión de la naturaleza teórica del problema seleccionado: la emergencia de un recuerdo textualizado valorativo de la antigüedad andina, a partir de lo cual exponemos varios argumentos que nos parecen demostraciones de la existencia de este hecho cultural. Este problema es culturalmente colonial; no disponemos de espacio para tratar el interesante asunto de una memoria conservada en objetos prehispánicos como quipus, textiles o keros. La trama expuesta solo nos autoriza a referirnos a estos materiales historiográficos como piezas esenciales de una memoria andina reconstituida gracias a la escritura histórica.

\section{El trabajo histórico dE ESPAÑoles, indígenAS Y MESTizos. Pensamiento, memoria e identidad}

La memoria es una cualidad psicológica y cognitiva inmanente y expresión de formas de pensamiento bistórico o mitológico, equivalentes a registros de la mente humana que permiten recordar hechos y acontecimientos importantes que han cohesionado culturalmente a sociedades del presente y del pasado. Esta característica de la psique individual y colectiva permite generar un recuerdo específico, 
almacenarlo y conservarlo para su uso social y/o ritual y reproducirlo a través de técnicas específicas. Este proceso implica proteger una evocación determinada y legarla para la posteridad a través de la enseñanza/aprendizaje (el sistema educativo), mediante tecnologías de la comunicación, a través de discursos narrativos altamente desarrollados, fundamentados y elaborados desde las altas esferas religiosas y políticas del poder.

En 1532 la sociedad cusqueña incaica era el grupo dominante que mantenía una sólida hegemonía a través de un enorme territorio denominado Tahuantinsuyo. La guerra sucesoria había sido definida por el triunfante Atahualpa. En aquel instante irrumpiría la hueste de Francisco Pizarro portando además de armas de metal, fuego y caballos, extraños papeles (una Biblia breviario) con símbolos ininteligibles que traían la noticia imposible de que el rey de España y el papa en Roma habían decretado bajo su propiedad estas tierras y sus habitantes. El texto escrito traía consigo el amanecer de un mundo nuevo nada favorable para la libertad, bienestar y autonomía de los andinos. Por su parte, en forma bastante distinta a lo que ocurría en Europa, los incas no conquistaban a otros pueblos para imponerles sus creencias, sus tradiciones; antes bien, establecían alianzas más o menos convenientes que aseguraban que los pueblos conquistados podían mantener sus deidades incorporando a las deidades cusqueñas, o bien esta tomaba también a la deidad y se la apropiaba (como el caso de Pachacámac o de Pariacaca), generándose un interesante vínculo relacional de tradiciones religiosas. Las memorias de los pueblos en esta interrelación negociada o pactada también se veían enriquecidas y ampliadas en sus contenidos, así como sus posibilidades parentales, materiales y económicas. Sin embargo, aquel año un profundo conflicto dividía tácitamente las altas cumbres del poder incaico: la crisis Quito-Cusco (Hemming 2004; Herrera Villagra 2019). Probablemente se estaba escribiendo, valga esta imagen metafórica, un

7 Véase Eliade (1996: cap. IX) y Durand (1993: 341-347). 
nuevo proceso político entre los incas que finalmente quedaría trunco por causa de la invasión de los conquistadores españoles.

En tal contexto, pensamos que existió una memoria oficial incaica que provenía desde el siglo XII o XIII con los mitos de la migración de linajes liderados por familias precursoras de la fundación del Cusco y de la organización de una nueva sociedad dirigida por una «Pareja Real». Una vez que aquella sociedad inició su proceso de estratificación y construcción de un poder todavía mayor, postuló a las deidades del Templo del Sol o Coricancha, principal institución religiosa, como las principales: Inti, Viracocha, Illapa, Pachamama, Pacarinas, Mallquis y Apus. Con el tiempo también tomaron a otras deidades para enriquecer y aumentar aún más su poder, como lo representa la anexión del Collao, Pachacámac, Chincha y Chimor. En consecuencia, según esta evidencia, existió una memoria étnica que correspondió a los grupos dominados o en alianza con los incas del Cusco, hecho que mantuvo en interacción constante ciertas correspondencias comunes como el culto a los muertos (momias), a los apus (montañas nevadas) y a la qochamama (el infinito e ignoto mar), que también arrastraba a otros sistemas simbólicos religiosos como el de las huacas, que se expresaban a través de la sacralización de seres, cosas u objetos provenientes de la cosmovisión andina centrada en la observación de la naturaleza. ${ }^{8}$

8 Vale le pena mencionar que el trabajo sobre los quipus y su comprensión cualitativa y cuantitativa continúa siendo un acto imprescindible para entender el sistema de pensamiento y comunicación de los incas. Por nuestra parte, pensamos que todavía es demasiado pronto para hipotetizar si las cuerdas anudadas de colores contienen relatos o narraciones históricas de carácter cualitativo. El manejo verbal, simbólico y mnemotécnico del Quipucamayoc, creemos, es la clave para comprender este asunto con mayor certitud. Véase Murra (2002) sobre un registro de la conquista española en Hatun Xauxa, y Urton (2017: 179182) sobre quipus ceques. En otro texto importante de Urton (2019), el autor propone el carácter de estadísticas administrativas de los quipus y las categoriza como fuente primaria. También es importante el texto editado por Pärsinnen y Kiviharju (2004), donde se incluyen transcripciones de quipus sobre materia económica y jurídica de los siglos XVI y XVII. 
A partir de este peculiar vínculo es interesante notar que la cronística española también fue parte de este fenómeno, como lo podemos visualizar en la siguiente tabla:

\section{TABLA 1}

Mitos ANDiNOS DE MigRACión SEGÚN TRES AUTORES ESPAÑOLES

\begin{tabular}{|c|c|c|c|c|}
\hline $\begin{array}{l}\text { \ Pedro Cieza } \\
\text { de León [1550] }\end{array}$ & $\begin{array}{c}\text { Cronología } \\
\text { Preinca }\end{array}$ & $\begin{array}{c}\int \text { Juan Diez de } \\
\text { Betanzos [1551] }\end{array}$ & $\begin{array}{l}\text { Cronología } \\
\text { Inca }\end{array}$ & $\begin{array}{c}\int \text { Polo de } \\
\text { Ondegardo } \\
{[1559-73]}\end{array}$ \\
\hline $\begin{array}{l}\text { ORIGEN: } \\
\text { Qollao } \\
\text { (¿Chucuito?). } \\
\text { Pucará, Ayaviri y } \\
\text { Sicuani. } \\
\text { Canas y Canchis. } \\
\text { MIGRACIÓN: } \\
\text { Pacaritambo. } \\
\text { Guanacaure. } \\
\text { Valle de } \\
\text { Aqhamama. } \\
\\
\text { FUNDACIÓN } \\
\text { DEL CUSCO }\end{array}$ & $\begin{array}{l}\text { Horizonte } \\
\text { Intermedio } \\
\text { Tardío } \\
\text { (aprox. } \\
900-1100 \\
\text { d. C.). }\end{array}$ & $\begin{array}{l}\text { ORIGEN: } \\
\text { El Collao } \\
\text { (Tiahuanaco). } \\
\text { El Oriente } \\
\text { mítico; lugar de } \\
\text { nacimiento del } \\
\text { sol. } \\
\text { MIGRACIÓN: } \\
\text { Condesuyo. } \\
\text { Andesuyo. } \\
\text { Cacha. } \\
\text { Urcos. } \\
\text { Llegada al Valle } \\
\text { de } \\
\text { Alcabicça. } \\
\text { Pacarictanbo. } \\
\text { Guanacaure. } \\
\text { Matagua. } \\
\text { FUNDACIÓN } \\
\text { DEL CUSCO } \\
\text { Partida a Puerto } \\
\text { Viejo, en la Costa } \\
\text { Norte: } \\
\text { desaparición de } \\
\text { Viracocha. } \\
\text { Fase Inca Tardía. }\end{array}$ & $\begin{array}{l}\text { Período } \\
\text { Inicial } \\
\text { (1100-1200 } \\
\text { d. C.) } \\
\text { Período } \\
\text { Medio } \\
\text { (1300-1400 } \\
\text { d. C.) } \\
\text { Período } \\
\text { Final } \\
\text { (aprox. } \\
\text { 1400-1500 } \\
\text { d. C.) }\end{array}$ & $\begin{array}{l}\text { ORIGEN: } \\
\text { El Collao, } \\
\text { Tiwanaku-Wari } \\
\text { (época perdida } \\
\text { en la memoria } \\
\text { indígena). } \\
\\
\text { MIGRACIÓN: } \\
\text { Cusco. } \\
\text { Urcos. } \\
\text { Yucay. } \\
\text { Jaquijahuana. }\end{array}$ \\
\hline
\end{tabular}

* Elaboración propia. 
En el cuadro anterior podemos verificar las tradiciones que estos tres autores españoles lograron rescatar gracias a su nivel de compresión lingüística, ideológica y cultural de las tradiciones que verbalmente les iban confiando los diversos testigos indígenas que rendían sus discursos de verdad. Este período de recopilación de testimonios de los incas vencidos es interesante porque involucra tres aspectos esenciales de un pensamiento auténticamente inca: el origen lacustre, la migración terrestre y la llegada al lugar del oráculo. Hemos organizado esta información de dos maneras: postulando cronologías relativas en los siglos inmediatamente anteriores al surgimiento de la etnia inca, y posteriormente el fin de su trayectoria migratoria y su consecuente asentamiento en el valle de Acamama (Garcilaso), como aparentemente fue llamado el territorio antes de recibir la denominación de Cusco.

\section{Aletheia/Veritas, Verdad/Yuyainin}

A partir de la sangrienta «entrevista» de los españoles con Atahualpa (15 de octubre de 1532), se introduce en los Andes una cultura foránea que entre sus elementos constituyentes era poseedora de un sistema explicativo basado en la historia escrita, la Biblia (la cultura del libro, la impresión, la lectura, el manuscrito, etc.), la ley románica y una tradición filosófica y teológica denominada patrística o escolástica. Esta situación inicial del contacto cristaliza con el empleo de la violencia y la coerción. Entre estos elementos de la cultura europea, es la escritura practicada en los Andes la que coadyuvó a generar un cambio radical que afectó a todas las comunidades étnicas y, de hecho, se transformó en uno de los ejes fundamentales de la nueva sociedad dominante, puesto que formó una memoria oficial de la colonización en el contexto inmediato que reconocemos como el discurso de la conquista. En términos trascendentes, la memoria oficial inscrita en la historiografía occidental 
oficializa la tarea pastoral de la evangelización e instituye el modelo de sociedad española; ambas tareas son llevadas a cabo con el desarrollo de las principales instituciones del Imperio español que por entonces crecía rápidamente: Consejo de Indias, Real Audiencia de Lima, Iglesia Católica... El hombre andino quedó sujeto a la legislación real y definido como vasallo en minoría de edad que requería de la paternidad de la Corona y del rey. ${ }^{9}$

La ideología de la monarquía y de la Iglesia controló transversalmente poblaciones imponiendo su lengua, técnicas de comunicación, economía-política, cosmovisión, etc. Todos los grupos andinos caerán bajo la presión del nuevo régimen y tendrán que aceptar sus ideas, tradiciones y costumbres, en forma obligatoria. Encontramos en los textos constitucionales del Primer Concilio Limense normativas y ordenamientos referidos a los individuos, como los que indican que: «dándole $[\mathrm{s}]$ a entender dentro del dicho término el herror y vanidad en que ha[n] viuido, adorando al sol y a las piedras y a las demás criaturas dejando al Criador» o «que son obligados a creer y guardar [...] (sic) [y] crean todo lo que los cristianos creemos» (Vargas Ugarte 1951: 9). Este cambio cultural y religioso, coercitivo, si bien fue definitivo no fue total (Duviols 1977; Estenssoro 2003). El fenómeno de dominación trajo aparejados, a la escritura y la pintura, el urbanismo y arquitectura, las instituciones políticas y la forma de su estructura económica, elementos de la cultura hispánica que regirán desde entonces y por tres siglos las vidas de los descendientes de los conquistados del siglo XVI. En este contexto, la lengua quechua será transformada en una metodología auxiliar que ayudó a los católicos a desarrollar sus campañas de evangelización, e inesperadamente también fue un importante espacio (reducto, intersticio, ángulo) de mantención de las tradiciones andinas - lo que nos parece un renacimiento heterodoxo de la memoria indígena- De hecho, la evangelización intervino directa-

9 Véanse Porras Barrenechea (1986) y Hemming (2004). 
mente en el espacio mental de las poblaciones andinas, pero no en todo ese territorio, en realidad. Por ello, creemos que las memorias autóctonas lograron trascender gracias a la lengua quechua que siguió siendo hablada por la población indígena en diferentes lugares del Perú colonial. Pensamos, a la vez, que la lengua castellana usada para imponer la cultura hispánica también resultó apropiada para la mantención de la cultura indígena, una entre varias paradojas coloniales. Así pues, impensadamente, las lenguas quechua y castellana fueron importantes herramientas ideológicas de la mantención de la cultura indígena y de su recuerdo o memoria. En suma: la semiosfera cultural ${ }^{10}$ que existió en la colonia no fue un producto absolutamente nuevo: arrastraba lo antiguo, recicló los residuos, reordenó lo disponible, vivificó lo descompuesto, tanto en el plano español como en el plano andino.

En efecto, la lengua quechua (o, en el altiplano, el aymara) fue un reducto de la vida cotidiana para la mantención de tradiciones en el mundo culto, así como en el mundo popular. La mantención de la lengua quechua, cooptada como lengua misional, universitaria o pastoral, fortaleció las expresiones íntimas del pueblo andino que mantuvo una identidad cercana a sus necesidades concretas de acuerdo con su cosmovisión y a sus vínculos con la tradición. Desde luego, la lengua quechua no mantuvo su prestigio de lengua culta u oficial, ya que el idioma castellano retuvo esa alta jerarquía, pero, en el ámbito de la República de indios, el quechua sí mantuvo una

10 Lotman escribe: «[...] no existen por sí solos en forma aislada sistemas precisos y funcionalmente unívocos que funcionan realmente. La separación de éstos está condicionada únicamente por una necesidad heurística. Tomado por separado, ninguno de ellos tiene, en realidad, capacidad de trabajar. Sólo funcionan estando sumergidos en un continuum semiótico, completamente ocupado por formaciones semióticas de diversos tipos y que se hallan en diversos niveles de organización» (Lotman 1996: 11). Vemos en la ecuación colonial y en plano textual relaciones culturales de distinto signo semiótico, por lo que el pensamiento de Lotman ayuda a entender a conjuntos diversos vinculados y en actividad incesante de producción de sentido. 
importancia secular, aunque soportando el peso de una operación de resemantización de su cuerpo lexicográfico (Torero 2005; 2007). Vemos, por ejemplo, que en el Arte y vocabulario [1586] hacia el final de la obra, en la sección final «Annotaciones», se registran las reglas de parentesco, consanguinidad y afinidad de las panacas y ayllus andinos, lo que a nuestro parecer es una recuperación cultural que surge del reconocimiento oficial. Esta pequeña muestra enseña que el quechua, incluso impreso en libros, como en la Doctrina Christiana de 1584, cumplió la función de recobrar, impensadamente, elementos culturales de la sociedad indígena.

A partir de 1570, la memoria incaica y la de otros pueblos andinos resultan de nuevo intervenidas severamente por el proceso organizacional virreinal (Merluzzi 2014). Por una parte, los incas del Cusco, particularmente la panaca de Paullu y otras panacas con semejante orientación, aceptaron la religión y cultura española para asegurar el reconocimiento legal de la Corona. Por otra parte, los incas rebeldes de Vilcabamba, que también intentaban negociar y aceptaron algunos proselitismos cristianos, fueron finalmente derrotados militarmente. En efecto, una tropa española, liderada por Martín García Óñez de Loyola y guiada por Paullu Inca, y secundada por guerreros cañaris, asaltó y destruyó el enclave de resistencia, asesinando sus guerreros más fieles. Capturado y engrillado del cuello, el último dignatario legítimo, el joven Túpac Amaru, resultó asesinado el 24 de septiembre de 1572, ejecutado en la plaza Haucaypata ante una multitud de españoles, indígenas y mestizos.

Un texto de esta época que afortunadamente quedó para la posteridad es la Instrucción al licenciado Lope García de Castro [1570], en el cual encontramos evidencia valiosa sobre variados aspectos de lo que pensaban los incas rebeldes de Vilcabamba. Por ejemplo:

Y porque la memoria de los honbres es devil y flaca e si no nos acurrimos [sic] a las letras para // nos aprovechar dellas en nuestras necesidades, hera cosa ynposible podernos acordar por estenso de todos los 
negoçios largos y de ynportançia que se nos ofresçiesen, y por esso, ussando de la brevedad posible, me sera neçesario hazer recopilaçión de algunas cosas neçesarias en las quales su señoria llevando my poder para ello, me a de hazer merçed de favoresçerme ante su Majestad en todas ellas, como a la clara de yuso yra declarado y relatado. ${ }^{11}$

Si bien esta opinión proviene de sus secretarios vinculados al gobierno eclesial y civil, no tenemos por qué dudar de una constatación grave: escribir resulta obligatorio hacia 1570. Así pues, el rey inca rebelde no titubea en utilizar este medio como forma diplomática para luchar por sus derechos. No resulta para nada un anatema demasiado clásico recordar que el patrimonio material de los incas fue expropiado, convertido en barras de metal para su envío a España o destruido por el violento accionar de los conquistadores y de los primeros encomenderos y oficiales de la Corona, con lo que se perdió parte importante de la cultura material donde se hallaban inscritas sus imágenes sagradas. Más bien, esa poderosa evidencia malograda y perdida nos recuerda que el concepto de agrafía resulta falaz para evaluar adecuadamente el antiguo sistema de signos andino (cf. Calvet 2013: Intro). Nosotros no creemos que el sistema alfabético sea, a pesar de su trascendental importancia, el único parámetro para definir la habilidad del hombre para inscribir mensajes en soportes de la memoria y el pensamiento. El eurocentrismo va bastante aparejado con la hegemonía de la escritura (Ong 2004: 1112, 16, 23-33, 36) de una manera sin duda análoga a lo que declaraba Elio Antonio de Nebrija en su Gramática Castellana [1492], respecto de la ecuación lengua-imperio.

En el plano jerárquico, más abajo en la escala social, otros regímenes de la memoria indígena también coexistieron con la verdad oficial políticamente hegemónica. Al parecer, para algunas etnias andinas el cristianismo resultó más significativo que sus antiguas formas de expresión. En este escenario, es posible pensar que se

11 Titu Cusi Yupanqui (1992: 3). Véase al respecto Herrera Villagra (2019: 69). 
produjo — considerando siempre a la lengua quechua y la memoria indígena como ejes fundamentales de tal sobrevivencia- una inesperada interpenetración cultural de los sistemas en juego, aunque también resulta cierto que el sector indígena fue quien se vio mayormente intervenido debido al cambio cultural forzado por el imperialismo español. Adicionalmente, es posible pensar que la resistencia de ciertos sectores de la población haya aportado sustancialmente a que aspectos de la cultura intervenida hayan fluido más libremente lejos del control español, experimentando igualmente cambios y transformaciones. Esta posibilidad no supone, de ninguna manera, el mantenimiento secular e histórico de una memoria precolombina prístina. Esta realidad tampoco nos sitúa forzosamente frente a una imposibilidad radical de estudiar el mundo antiguo. El cambio y la transformación ocurrieron, sin duda. Y así la historia como disciplina científica que analiza documentos tiene sentido y lógica. El punto crítico es que el poder español fracasó en desarticular totalmente la cultura tradicional andina, mientras que los pueblos nativos consiguieron mantener su tradición. Este hecho esencial es el que aquí defendemos sin radicalismos ni esencialismos. Creemos que simplemente la cultura logró perdurar gracias al utillaje colonial, lo cual constituye un gran logro social. La memoria tuvo que haber sido un gran ángulo de apoyo para este tipo de sociedades tradicionales. Si tales memorias, en fin, se vieron alimentadas por otras tradiciones, estas tuvieron que haber sido también creadas en la época colonial con o sin influencia de las instituciones dominantes.

En el Manuscrito Quechua de Huarochirí [¿1598-1608?] encontramos una idea interesantísima sobre memoria, escritura (Quillcacta) y archivo, como repositorio físico de la evocación cultural:

1. Si en los tiempos antiguos los antepasados de los hombres llamados indios hubieran conocido la escritura, no se habrían ido perdido todas sus tradiciones como ha ocurrido hasta ahora. 
2. Más bien se habrían conservado, como se conservan las tradiciones y ([el recuerdo de]) la antigua valentía de los buiracochas que aún hoy son visibles.

3. Pero como es así, y hasta ahora no se las ha puesto por escrito, voy a relatar aquí las tradiciones de los antiguos hombres de Huarochirí, todos protegidos por el mismo padre, la fe que observan y las costumbres que siguen hasta nuestros días. ${ }^{12}$

Que hayan quedado escritas estas narraciones en el soporte mismo de la historia colonial nos parece una latencia de conservación, aun cuando el hombre andino se veía asediado constantemente por extirpadores, encomenderos y curacas (véase Guaman Poma 2006: 488, 655, 865). Todas las fluctuaciones de las culturas relacionadas colonialmente pudieron haber sido las responsables de variaciones en términos locales de los registros de la memoria, puesto que en perspectiva cada área regional pudo haber tenido dinámicas particulares y exclusivas, así el caso de Cusco (diócesis de Cusco), área central de la población indígena en la época colonial, Lima y Trujillo en la costa central, o Puno y Juli en la puna lacustre, por ejemplo. Más aún, esta evidencia se hace todavía más fuerte cuando estudiamos la cultura de pueblos y aldeas pequeñas y más alejadas geográficamente de los centros urbanos de control, donde la cultura tradicional pudo sobrevivir menos riesgosamente ante el ojo panóptico del poder eclesial, civil y militar español. Pero allí es donde lastimosamente escasean los escritos coloniales. Estudiando relacionalmente estas variables podría llegarse a una cierta imagen de conjunto de estos movimientos heterogéneos, lo que requiere de muchas miradas disciplinarias, sobre todo estrategias investigativas con experiencia de campo y con gran pericia en el trabajo de archivos de diversos repositorios que sobreviven de la época colonial. ${ }^{13}$

12 Versión de Taylor (1999: 3).

13 Nosotros hemos venido revisando en el Archivo Regional del Cusco el Catálogo del Fondo Corregimiento (siglo XVI), del cual hemos tomado algunas infor- 
Por su parte, la existencia de alternativas coyunturales de la memoria también pudo haber creado flujos culturalmente específicos que reflejaran sus políticas, sus efectos, las reacciones contra ella, o las acciones a favor de las memorias locales. Pero la existencia inextricable de una Verdad Única (y esto conviene plantearlo así, ya que estamos hablando del catolicismo colonial), nubla, oscurece y complica bastante la observación y la distinción de tipos de pensamiento que pudieron contradecir abierta o encubiertamente su lógica de intolerancia. El siglo XVII es un siglo extraño, cuando se le mira con demasiada aprehensión. Hay hechos interesantes más globales que ayudan a comprender lo que ocurre en la América hispana, como es el caso de la witch-bunt o caza de brujas, lo que calza bien con el movimiento de extirpación de idolatrías en los Andes. La crisis económica general en Europa es también otro evento importante sin lo cual no entendemos la historia colonial de América (Trevor-Roper 2009: cap. 2). El problema de España en los Países Bajos es otro ejemplo. Finalmente, el cambio social propiciado por la Reforma y la Contrarreforma también ofrece buenos ventanales para observar la realidad de este siglo de hambre, ciencia y colonialismo. España no era la única monarquía que pretendía usufructuar del Nuevo Mundo.

En la práctica, la escritura se empleó para desarrollar múltiples labores administrativas, económicas, jurídicas, teológicas y literarias, su carácter social fue insustituible, y fue aprovechada por los autores andinos estudiados quienes conocían bien el patrimonio de la palabra antigua (despojada de su sistema de signos que la soportaba o complementaba) para reinterpretar precisamente la memoria de sus antepasados. Probablemente esta coincidencia azarosa, una memoria renacida inesperadamente, o combinación deliberada, o

maciones tocantes a cuestiones de pleitos, testamentos y juicios, solo a modo de información primaria de base. En lo sucesivo pretendemos usar con mayor conocimiento de causa estos documentos. 
ambas, produjeron unas formas de pensar que reunieron visiones ideológicas opuestas formulando hibridismos que, producto de una incierta solución de conflictos, se fusionaron en una forma cultural nueva, aparentemente contradictoria, que no podía de otro modo nombrar un presente colonial crítico. Negar esta posibilidad práctica podía significar el fin definitivo de la cultura indígena, pero, inversamente, se terminó abriendo una brecha dogmática blanda llena de intersticios por los cuales penetró una agencia indígena con capacidad para resistir y negociar alternativamente. Este hecho cultural configura el fenómeno del surgimiento de discursos históricoliterarios heterogéneos que tuvieron tres consecuencias formales: 1) efectos disolventes en muchos aspectos de la memoria antigua dado su eje de articulación central: el cristianismo; 2) paradojalmente, el recurso de la palabra escrita en manos indígenas recobró de modo inesperado varios aspectos de esta memoria, dado que la población continuó empleando su cultura y lengua para comprender su presente colonial; y 3) esa memoria escrita cuando fue pública (caso del Inca Garcilaso de la Vega) tuvo la virtud de influir en el recuerdo y la mentalidad de la población andina, especialmente en el conflictivo siglo XVIII. De estos hechos deducimos que una tecnología comunicativa sustituyó a otra en el plano de la conservación de las memorias, que una ideología destruyó a la otra en el plano de la conquista política y que un sistema religioso intentó destruir al otro que lo precedía. Pese a estos actos típicamente colonizadores, no fue posible doblegar a la población a una borradura absoluta de los registros de la memoria, incluso habiendo destruido los sistemas materiales de la comunicación. Justamente por esta razón los sistemas de pensamiento terminaron amalgamándose hasta generar socialmente una percepción de doble matriz en diferentes áreas del saber y del conocimiento. ${ }^{14}$

14 Rolena Adorno y Raquel Chang-Rodríguez, quienes han estudiado al Inca Garcilaso y a Guaman Poma de Ayala, piensan que «la escritura alfabética era por 
Ahora necesitamos brevemente volver la mirada a las obras estudiadas en nuestra tesis: los Comentarios Reales de los Incas [1609], la Relación de Antigüedades deste Reyno del Pirú [ca. 1613] y la Nueva Corónica y Buen Gobierno [1615].

\section{LA MEMORIA ANDINA COLONIZADA}

Es necesario entender que la adopción de la escritura como hecho cultural fue parte de una compleja solución de continuidad que, en primer término, opuso dos sistemas semasiográficos caracterizados como no complementarios entre sí: el «sistema de signos andino» y el «sistema de escritura alfabética», que presuponen, respectivamente, concepciones de saber, pensamiento y memoria soportadas en técnicas distintas. Este proceso de choque fue resuelto mediante la imposición de un poder culturalmente diferente que no proponía diálogo, consenso ni tolerancia, valoración o respeto, sino exclusión, denigración y destrucción de lo distinto. El vector religioso es el principal responsable de esta situación histórica. Pese a todo, la escritura se transformó en una herramienta para la recuperación de la tradición andina, y también sobrevivieron muchos objetos comunicativos del pasado: quipus, keros, textiles, nueva paradoja museológica y arqueológica.

El Inca Garcilaso representa claramente la idea que nos hemos ido formando de autor, en cuanto escritor, artífice y creador de textos literarios de factura europea editados en su momento. Poseyó una formación cristiana tanto en los Andes como en España. De

excelencia la institución de la colonización» (Adorno 1992: 21) y que «los indios ladinos, versados en lenguas nativas — quechua, aimara, náhuatl- y en las diversas formas de conservar el saber de la culturas americanas —quipus, glifos, libros pintados - y al mismo tiempo capacitados para hablar y escribir el castellano» (Chang-Rodríguez 2005: 79). Un enfoque que nosotros hemos querido profundizar un tanto más. 
niño tuvo profesores privados, con su padre trabajó como secretario escribiendo cartas, también obtuvo una educación por parte de su tío materno en el seno de su familia cusqueña. Años después en España, luego de participar en la guerra en el sur (en las Alpujarras) y del retiro militar, se dedicó a criar caballos en Montilla, producir y vender vino, a leer, reflexionar, traducir y escribir desde entonces varias obras. Su contexto fue inmejorable: el renacentismo humanista italiano y español, y sus amistades jesuitas, por entonces una orden muy influyente, notables intelectuales del Siglo de Oro español. Por su contenido histórico y su circulación concreta en el ámbito de la cultura del libro, varios autores le han dedicado una lectura crítica y atenta, por ejemplo: Hernández (1993), Cerrón-Palomino (2013), Chang-Rodríguez (ed. 2010) y Mazzotti (ed. 2010; 2016). El método de escritura del Inca Garcilaso fue muy moderno, según nuestro punto de vista, ya que utilizó no solo una perspectiva histórica, sino también intercultural y lingüística (Herrera Villagra 2018). Sus informaciones reposaron en su propia memoria individual y familiar, en la experiencia ganada en las letras con su traducción del libro de León Hebreo y su historia de La Florida, así como su conocimiento de obras históricas clave: el libro malogrado de Blas Valera, Cieza de León [1553], Zárate [1555; 1557], Acosta [1590], entre otras. Al paso, podemos indicar que su traducción de León Hebreo fue censurada por el Santo Oficio e incluida en el famoso Índice de libros prohibidos (González Vigil 2016: 87). De una manera realmente paradigmática destaca el significativo intercambio epistolar con su familia materna, aspecto que nos parece de primer orden en relación con el recuerdo y memoria de las panacas del Cusco colonial del siglo XVI y comienzos del XVII. Finalmente, su Historia general del Perú [Córdoba, 1617] también constituye una pieza rica en estilo, lenguaje e informaciones, libro que tuvo ni más ni menos que la aprobación personal del rey de España, Felipe III, en 1614.

La siguiente cita, lúcida e irónica, representa vivamente su 
intelecto:

Reprendiendo yo mi memoria por estos descuidos, me responde que por qué le riño de lo que yo mismo tengo la culpa; que advierta yo que ha cuarenta y dos años que no hablo ni leo en aquella lengua. Válgame este descargo para el que quisiere culparme de haber olvidado mi lenguaje. Creo que el tigre se llama uturuncu, aunque el Padre Maestro Acosta da este nombre al oso, diciendo otoroncos, conforme a la corruptela española; no sé cuál de los dos se engaña; creo que Su Paternidad. ${ }^{15}$

Pachacuti Yamqui Salcamaygua también nos parece sumamente importante para adentrarnos en los discursos indígenas que levantaron aquellos individuos que estuvieron presentes en el campo de batalla de las letras. En el caso de Pachacuti Yamqui estamos en presencia de una persona joven que pudo haber sido reclutada en las labores evangelizadores por el vicario Francisco de Ávila, el mismo que patrocinara la escritura del Runa Yndio Niscap. Este autor tuvo que haberse instruido en alguna parroquia de indios donde se realizaban labores educativas enfocadas en la formación de indígenas al servicio de la Iglesia católica. Su pertenencia étnica y territorial al área de Canas y Canchis también resulta tremendamente importante porque gracias a ello logramos trascender informaciones puramente cusqueñas e incaicas, y extendemos nuestro radio de conocimientos a otras etnias y a sus respectivos procesos de cambio cultural de lo andino a lo hispánico. Su ardiente militancia cristiana resulta admirable, pero a la vez intrigante porque su conocimiento sobre tradiciones mitológicas andinas es bastante rico en detalles. Si bien es cierto que su narración está cuidadosamente estructurada desde la crítica antimitológica, de todos modos, los ciclos antiguos arrastran consigo vestigios significativos de las tradiciones precristianas. El uso de algunos dibujos de

15 De la Vega (1985: 189). 
factura occidental a pesar de su precariedad técnica, indican una formación pedagógica en alguna institución educativa de la Iglesia. Particularmente, gracias al estudio de esta obra podemos conocer los vínculos de la memoria tradicional entre el altiplano y la sierra, área más que importante para aclarar varios asuntos del pasado del Tahuantinsuyo. Sus informaciones nos resultan sumamente válidas para aclarar una memoria andina colonial. Las ediciones y estudios de Pierre Duviols y Cesar Itier (1993), Carlos Araníbar (1995), así como Rosario Navarro Gala (2007) y Jan Szemiński (2019) son insustituibles.

En la siguiente cita el autor asume una identidad profundamente cristiana:

Yo, como nieto y descendiente legítimo de los susodichos, siempre desde que soy hombre he procurado ser firme y estable en el misterio de nuestra santa fe católica, exhortando a los prójimos a que fueran más adelante en ser buenos cristianos con intención y celo de guardar los 10 preceptos de la ley de dios, creyendo en Jesucristo nuestro Señor a imitación de nuestra santa madre iglesia de Roma. De modo que la santa iglesia romana cree lo que yo, don Juan de Santa Cruz, creo. Y, así, en ella quiero vivir y morir en el temor de dios trino y uno, que vive y reina para siempre sin fin. ${ }^{16}$

La obra de Guaman Poma de Ayala es también paradigmática. $\mathrm{Al}$ afirmarlo no estamos conectados con la idea de que lo prehis-

16 Pachacuti Yamqui Salcamaygua (1993: 5). La fecha aproximada de 1613 fue deducida por Marcos Jiménez de la Espada (1879: XLIV). Duviols e Itier (1993: 18-20) y Szemiński (2019: 25) han dudado de ello. Szemiński, comentando los argumentos de los antes mencionados, indica que la obra pudo ser escrita entre 1610 y 1647 (2019: 23-25), pero agrega finalmente que deducciones y suposiciones son imposibles de verificar. Sin embargo, 1613 sigue siendo considerada una fecha aproximativa tradicional. Para simplificar el argumento y circunscribirlo al análisis etnohistórico aquí seguimos las grafías de la edición de Duviols e Itier (1993), si bien entendemos que en la obra de Szemiński (2019) hay mayor rigor lingüístico-filológico. 
pánico trascendió sin cambios en los tres siglos coloniales, puesto que la transformación cultural operó sin lugar a dudas, tanto en la República de indios como asimismo ocurrió, aunque ciertamente en menor grado, en la República de españoles. La observación del plano de las ideologías, identidades e imaginarios, así como el examen del plano de la lengua, lo simbólico y lo comunicativo, se constituyen en evidencias importantes sobre la cultura andina colonial. Nos enseña que la población autóctona no fue tan inerme como algunos autores lo creen, ni fue tan aculturada como también otros lo sostuvieron en su momento. Hubo más agencia, más creatividad, más capacidad para eludir el ojo censor eclesial y trascender los márgenes que el gobierno colonial estrechaba alrededor de los andinos. Su trabajo escrito, tanto como su trabajo visual, demuestra que Guaman Poma de Ayala conoció bien lo que todavía subsistía en el segundo y tercer tercio del siglo XVI. Si bien se trata de una persona tremendamente convencida de su cristianismo, tampoco cabe alguna duda de la veracidad de sus informaciones aun cuando estas quedasen recubiertas de la forma cultural de la escritura y prosa europea que subrepticiamente lo hegemonizaba todo. Las oralidades que quedan encapsuladas en el trabajo escrito fueron modificadas por el patrón ideológico español. Otro hecho interesante que relevamos es su manifiesto desacuerdo con el proceso de mestización que reprobadada drásticamente. Los estudios de López-Baralt (1993), Ossio (2008) y Szemiński (2008) me parecen cruciales, mientras que la edición y estudio de John V. Murra, Rolena Adorno y Jorge Urioste (2006) es la mejor fuente de estudio de la «Carta al Rey». ${ }^{17}$

La siguiente cita exhibe una historia andina cuyo origen es cristiano:

17 Sin olvidar el excelente recurso en línea: <http://www5.kb.dk/permalink/2006/poma/info/es/frontpage.htm>, actualizado por Adorno y Boserup. 
Y ací, cologado de uarios descursos, pasé muchos días y años yndeterminando hasta que uencido de mí y tantos años, comienso deste rreyno, acabo de tan antiguo deseo, que fue cienpre buscar en la rudeza de mi engenio y ciegos ojos y poco uer y poco sauer, y no ser letrado ni dotor ni lesenciado ni latino, como el primero deste rreyno, con alguna ocación con que poder seruir a vuestra Magestad, me determiné de escriuir la historia y desendencia y los famosos hechos de los primeros rreys y señores y capitanes nuestros agüelos y des prencipales y uida de yndios y sus generaciones y desendencia desde el primero yndio llamado Uari Uira Cocha Runa. ${ }^{18}$

Las citas precedentes solo son un pequeño índice del conjunto de evidencias que hemos encontrado al realizar nuestras lecturas críticas de estas obras, lo que en el futuro seguiremos comunicando. Creemos que estas obras en sí mismas representan actos de reivindicación que involucran dos referentes culturales contradictorios y en tensión permanente como el fruto de subjetividades coloniales. El estudio de estas obras requiere, desde luego, un espacio amplio en un libro de texto que examine en detalle diversos aspectos apenas aquí esbozados. Tareas para el futuro. La riqueza de las informaciones ofrecidas nos permite afirmar, junto a muchos especialistas que llevan décadas estudiando estas obras, que son realmente imprescindibles en el campo de la historia andina y por ello merecen toda nuestra atención (cf. Herrera Villagra 2016).

La tabla 2 reúne una visión de conjunto de las ideas que suscribimos en este ensayo (compárese con la tabla 1).

18 Guaman Poma de Ayala (2006: 6). 
TABLA 2

Diversos ASPECTOS DE LA CULTURA ANDINA RECUPERADOS GRACIAS AL RESCATE DE LA MEMORIA, SEGÚN TRES AUTORES INDÍGENAS/MESTIZOS

\begin{tabular}{|c|c|c|}
\hline $\begin{array}{c}\int \text { Inca Garcilaso de la } \\
\text { Vega - } 1609\end{array}$ & $\begin{array}{c}\text { \Juan de Santa Cruz } \\
\text { Pachacuti Salcamaygua - } \\
1613\end{array}$ & $\begin{array}{l}\int \text { Felipe Guaman } \\
\text { Poma de Ayala - } 1615\end{array}$ \\
\hline $\begin{array}{l}\text { Migración: Titicaca - } \\
\text { Valle de Acamama. }\end{array}$ & Influencia Tiwanaku / Wari. & $\begin{array}{l}\text { Los meses del año } \\
\text { lunar. }\end{array}$ \\
\hline $\begin{array}{l}\text { Expansión Inca-- } \\
\text { Creación del Tawantin- } \\
\text { suyu. }\end{array}$ & Purun Pacha. & $\begin{array}{l}\text { Las eras culturales } \\
\text { preinca e inca. }\end{array}$ \\
\hline $\begin{array}{l}\text { Descripción de la Qhapaq } \\
\text { Cuna. }\end{array}$ & Canas y Canchis. & Deidades andinas. \\
\hline $\begin{array}{l}\text { Salud, derecho, política, } \\
\text { astronomía, arquitectura, } \\
\text { economía. }\end{array}$ & $\begin{array}{l}\text { Viracocha / Hombre } \\
\text { Barbudo. }\end{array}$ & Los mallquis. \\
\hline $\begin{array}{l}\text { Lenguas andinas: } \\
\text { quechua, aimara, puquina. }\end{array}$ & Guerras rituales. & Minka, ayni, mita. \\
\hline Mestizajes. & Evangelización. & $\begin{array}{l}\text { Sistema de signos } \\
\text { andino / Sistema } \\
\text { alfabético de escritura. }\end{array}$ \\
\hline Literatura, historia, poesía. & Extirpación de idolatrías. & Buen gobierno colonial. \\
\hline
\end{tabular}

* Elaboración propia.

La presentación resumida de algunos aspectos de la cultura indígena en la tabla anterior, exhibe un conjunto aceptable de elementos para quien admita nuestras sugerencias respecto del significado que ofrece una lectura analítica de estas obras clásicas de la literatura peruana. Desde una cima ideológica andina (las mito-historias de la 
migración de los protoincas y la fundación del Cusco) hasta aspectos complejos de las formas de gobierno indígena (expansión del Tahuantinsuyo), así como de la morfología de la sociedad andina, la organización económica de las unidades étnicas, el carácter histórico y mítico del funcionamiento de las formas políticas y religiosas, incluidos aspectos simbólicos, artísticos y estéticos de la cultura antigua, emergen completando eventualmente un nuevo ciclo de existencia, esta vez en un contexto más difícil de sobrevivencia y bajo otro ritmo de vida encapsulado en la escritura europea.

Una vez dicho esto cabe preguntarnos lo siguiente: ¿Estas expresiones textuales-documentales son aisladas o tuvieron efectos prácticos en la cultura del siglo XVII? Observamos que la escritura y la cultura del libro fueron importantes puntos de apoyo para quienes vieron en estas tecnologías de la comunicación la posibilidad de continuar practicando, recreando y protegiendo tradiciones en los nuevos contextos que cada generación de sujetos debió enfrentar durante la vida colonial. Posiblemente el éxito editorial en Europa de los Comentarios reales [1609] del Inca Garcilaso, obra que fue traducida a varias lenguas, como el inglés, francés y holandés, fue cada vez más constante a lo largo de todo el siglo XVII. Y al parecer en el siglo XVIII llegó a ser paradigmática, tanto así que después de la rebelión de Túpac Amaru II y Túpac Katari, en 1782, la obra de Garcilaso fue proscrita y hasta quemada (Guibovich 1990-1992: 103). Esto refuerza la idea de que la «pasión por la escritura» (Gruzinski 2013), y desde luego por la lectura, y el saber que ella entrañaba, fue cada vez más esencial al interior de las diversas expresiones de la cultura colonial americana y, al parecer, también de la cultura iluminista europea. El actual concepto de «intelectuales indígenas» (Ramos y Yannakakis 2014: 4; Lamana 2019: Intro) por supuesto aparece abierto en toda su riqueza literaria, agencial y sociológica. ${ }^{19}$

19 Ramos y Yannakakis escriben: «When indigenous intellectuals wrote and acted, they made choices. In making those choices, they innovated using materials, discourses, and traditions available to them. Some of these intellectual resources 


\section{REFLEXIÓN FINAL}

Escribió Aristóteles: «La memoria es el escribano del alma». Creemos que tan sabias palabras siguen siendo válidas en nuestra época. La memoria andina colonial no es estrictamente la memoria de las poblaciones de antes del siglo XVI; es una mezcla de dos sistemas de pensamiento: el sistema sagrado andino y la religión cristiana española, cuya compleja composición y resultado, teóricamente vinculados y mezclados por el sincretismo, la aculturación y el mestizaje, expresa peculiares formas de un pensamiento colonial que lograron acomodar, componer o armonizar hombres críticos de estas realidades. Por lo que no podemos continuar sesgando el hecho de que tenemos ante nosotros un sistema dual religioso-cultural que creó nuevas realidades conflictivas. Estas realidades conflictivas implican actitudes heterodoxas, según hemos indicado. La aceptación, la resistencia y la ignorancia son tres actitudes básicas que nos pueden ayudar a entender otras actitudes ambivalentes, oportunistas o pragmáticas. Consensos, negociaciones y acuerdos pudieron haber matizado el difícil mundo de la imposición y la aceptación. El esquema «dual» aquí propuesto implica un horizonte complejo de actitudes y conductas, no una dicotomía radical. Entender cómo se representó el hombre andino colonial su propio contexto sociohistórico nos debiera ayudar a entender esa sociedad marcada por asimetrías naturalizadas: una coexistencia bicultural llena de contradicciones y fe. Ahondar en los contenidos de obras históricas españolas, mestizas e indígenas, donde se expresan significativas evocaciones del pasado, nos debe ayudar a observar necesariamente que dentro del texto histórico

were rooted in the past. The work of indigenous intellectuals was to transform these resources according to the circumstances of the colonial present» (Ramos y Yannakakis 2014: 4). Por su parte, Lamana anota: «While indispensable to the study of colonialism in the Andes, the relevance of these two intellectuals goes beyond that. Garcilaso and Guaman Poma are in a way comparable to thinkers like Aristotle and Plato» (Lamana 2019: 9). 
existen dos dimensiones que engloban: 1) un conjunto de informaciones que se están refiriendo a las tradiciones andinas más antiguas, y 2) una forma de representarse el mundo que pese a todo debía mantener mínimamente un orden esencial que solo la fe podía mantener latente y vivo. Ambas son funciones esenciales de la memoria que todo pueblo defiende para continuar existiendo y enfrentando los desafíos con la tradición como punto de apoyo, pese a la violencia, la explotación y el fanatismo.

A principios del siglo XVII la escritura, el principal medio de comunicación occidental, contribuyó en los Andes a que la población lograse reinterpretar la memoria de los antepasados y sus formas de vida, a fijarla y secularizarla. Sin un medio de comunicación propio tuvieron que tomar el europeo y utilizarlo para fines de interés particular. Este es un hecho trascendente del expediente del cambio cultural en los Andes del seiscientos. Como campo del saber que provenía de otra cultura, esta forma de expresión, es decir, la escritura indígena andina, tuvo que afiliarse a reglas y normas discursivas y gramatológicas de las formas de pensar europeas. El intelecto indígena andino tuvo que borrar algunos aspectos de sus formas de pensamiento antiguo para iluminar otros, emplearlos y legitimarlos; se vio obligado a decir lo justo y lo correcto creando una tropología propia, cercana semióticamente al discurso oficial. El control eclesial y oficial limitó fuertemente a los andinos en sus impulsos culturales más íntimos. El pensamiento hubo de escindirse y manifestarse en dos esferas coexistentes simultáneamente. La semiosis colonial pudo desplegar un macrocosmos de significados oficiales, pero a la vez también produjo nuevos significantes que enriquecieron el lenguaje colonial, los que quedaron encriptados en estructuras ideales muchas veces dotadas de doble significado. La memoria indígena renacida colonialmente para reafirmar sus valores tuvo obligadamente que acudir a la ideología oficial para proponer un discurso pragmático que lograse obtener una redención social. Tuvo que basarse en la historiografía española para sostener 
legítimamente sus bases epistemológicas. Y lo hizo brillantemente al integrar tradiciones que aseguraron el recuerdo del pasado andino. Los documentos que Titu Cusi Yupanqui dejó hacia 1570 (Herrera Villagra 2019), abren para nosotros un espacio propicio para estudiar el surgimiento de la literatura indígena en el amanecer de una memoria andina colonial. Nuestra interpretación de las informaciones etnohistóricas que nos entregan el Inca Garcilaso, Guaman Poma o Pachacuti Yamqui, propone que el conocimiento de la cultura andina que estos autores representaron literariamente trascendió gracias precisamente a la cultura escrita de la época estudiada, la que fluyó de múltiples modos por el tejido social rehaciendo el complejo entramado de las tradiciones que quedaron aisladas en el plano de las oralidades. Esto pudo ocurrir así, estimamos, debido a que un ambiente crecientemente docto permitía a escritores y obras eludir los censores eclesiales y políticos, obtener su aprobación, o permanecer clandestina incluso. Espacios de creatividad literaria surgieron y experimentaron diferentes destinos. Creemos que entre la cultura y la historia, la memoria de los pueblos es la que sutura los desgarros y los cortes que difunde el cambio social, y nos permite estudiar su anatomía con algún detalle. Al interior de la ciudad letrada del siglo XVI un autor podía maniobrar intelectual y políticamente de manera inteligente amparado en la utopía cristiana, lo mismo que jurídicamente, como lo demuestran con amplitud los famosos y molestos pleitos de andinos contra particulares españoles. Ello ocurrió de una manera inadvertida, subrepticia, pero tuvo efectos positivos en la conciencia de los andinos ligados al campo problemático aquí estudiado.

Al releer el Manuscrito Quechua de Huarochirí nos damos cuenta de las posibilidades que se abrían y que se refrendaban experiencia tras experiencia gracias al útil campo de la memoria registrada a través de este artefacto cultural tan significativo para los hombres del período: la escritura de la historia. Estos hechos característicos de los siglos XVI y XVII constituyen un debate colonial perma- 
nente en el que se pueden encadenar las vicisitudes de la escritura indígena. La fe o la economía espiritual de la época proporcionaron un marco relativo de agencia social que daba la posibilidad de enunciar una identidad indígena. Las letras andinas, en fin, reflejaron el pensamiento vivo de los grupos sociales que interactuaban intercambiando símbolos de una manera fluida, sobre todo mediante el fondo de estas enunciaciones, lo que quizás represente el paradigma inamovible de lo escrito. El ambiente propicio que la educación y las artes del período humanista instauraron consiguió que aspectos de la cultura andina fuesen aceptados e incorporados en la cultura cotidiana, ya que tales elementos se consideraban cristianizados o inocuos. Hubo dominación militar, política y económica, pero sin una hegemonía cultural completa. La doctrina cristiana, el mundo natural y sobrenatural que abarcaba, fue el factor determinante que les permitió a estos cultos escritores apropiarse de la cultura occidental, y desde este concepto de mundo hubieron de componer una cosmovisión ideal a partir de sus mundos subjetivos, sin desanclarse de la realidad social a la cual pertenecían. Las historias míticas, celebraciones y ceremonias, los conocimientos vinculados con la alimentación, salud, parentesco, tecnología, economía y religión, hasta la percepción política de las diversas tipologías sociales, todo ello muestra que la memoria andina permaneció viva aunque oculta en aquellos espacios que pudieron reivindicarse para la protección de una cultura que no podía morir, porque de ello dependía el futuro concreto y objetivo de la población andina, mucho más allá de cualquier Pachacuti que pudiese afectar al mundo y a la naturaleza.

¿Tuvo continuidad histórica la adopción de la escritura, la utilización de los estilos narrativos historiográficos o literarios, por parte de sujetos pertenecientes al estamento indígena o mestizo? Es decir, ¿hubo otros hombres andinos que utilizaron esta preciada herramienta cultural para fines de reivindicación étnica, política o económica, más allá de lo valórico, intelectual e individual, más allá del ego del escritor? La respuesta es que sí los hubo. Entre otras 
obras que hemos identificado, la poesía de Amarilis, las obras de teatro en lengua quechua como el Ollantay [ca. 1770], las cartas de Vicente Chimú Cápac, Fray Calixto Túpac y José Gabriel Condorcanqui Noguera, así como los libros de Domingo Choquehuanca o Justo Sahuaraura, todos producidos entre ca. 1620 a 1830, a la par de un sinnúmero de obras españolas o criollas, muestran que la lucha por la memoria histórica andina continuó en otros contextos, enfrentando problemas coyunturales, utilizando otros estilos, intentando reflejar la vida de la sociedad andina, discrepando con la Autoridad Regia, fomentando el avance hacia otras formas de interpretar la vida política y económica, hacia incluso la superación del estatus colonial tal como podemos interpretar los edictos de Túpac Amaru II contra la esclavitud, la mita y la Corona española.

La intersección de culturas más allá de sus conflictos en el orden formal económico-político no canceló la posibilidad de que nuevos fenómenos fueran desarrollándose, como la preservación de las tradiciones locales, uso de las lenguas indígenas, protección de las formas míticas del pensamiento, el hibridismo religioso, etc. Estos importantes asuntos significativamente restan fuerza de acción a la clasificación de las culturas coloniales coexistentes en dicotomías, antinomias o claroscuros parciales. Las soluciones de continuidad entre los modos de la sociedad española, los modos de la sociedad andina y los espacios intermedios de simultaneidad social (de negociación, de aceptación) muestran muchísimas posibilidades de un cambio cultural que evaluamos como multilineal; en efecto, las muchas variables en juego interactuaron con profusa intensidad. El cambio y trasformación se generaron en múltiples direcciones. Es importante seguir esas simultaneidades y trayectorias para reconstruirlas. Su composición altamente heterogénea no puede ser estudiada con verdadera eficacia si no comprendemos debidamente este hecho social de tanta envergadura, según la evidencia etnohistórica nos muestra. Los siglos XVI y XVII deben continuar examinándose a la luz del dinamismo cultural propuesto en estas líneas. 


\section{REFERENCIAS}

\section{FUENTES PRIMARIAS}

ANÓNIMO

2014 Elegía Apu Inka Atawallpaman. Primer documento de la resistencia inka (Siglo XVI). Publicado por Odi Gonzáles. Lima: Grupo Pakarina; CLACS; Universidad Nacional Mayor de San Marcos.

ANÓNIMO

[1586] Arte y vocabulario en la lengua general del Perú llamada quichua. Lima: Imprenta de Antonio Ricardo.

Betanzos, Juan de

2015 [1551] Juan de Betanzos y el Tabuantinsuyo. Nueva edición de Suma y narración de los incas. En: Francisco Hernández Astete y Rodolfo CerrónPalomino (eds.). Lima: Pontificia Universidad Católica del Perú.

Cieza de León, Pedro

1996 [1553] Crónica del Perú. Primera Parte. Lima: Pontificia Universidad Católica del Perú; Academia Nacional de la Historia.

De la Vega, Inca Garcilaso

1985 [1609] Comentarios Reales de los Incas. Prólogo, edición y cronología de Aurelio Miró Quesada. Caracas: Biblioteca Ayacucho.

Doctrina Christiana, Y CATECismo PARA LA instrVCCiOn DE LOS indios... 1985 [1584] Imprenta de Antonio Ricardo. Edición facsimilar. Lima: PetroPerú.

GonZÁlez Holguín, Diego

1989 [1609] Vocabulario de la lengua general de todo el Perú llamada lengua qquichua o del Inca. Lima: Universidad Nacional Mayor de San Marcos.

Guaman Poma de Ayala, Felipe

2006 [1615] El primer Nueva Corónica y Buen gobierno. En: R. Adorno y J. V. Murra (eds.). México: Siglo XXI.

2005 [1615] Nueva Corónica y Buen Gobierno. Edición y Prólogo de Jan Szemiński.

México: Fondo de Cultura Económica. 
Pachacuti Yamqui Salcamaygua, Juan de Santa Cruz

1993 [ca. 1613] Relación de Antigüedades deste Reyno del Pirú. Estudio etnohistórico y lingüístico de Pierre Duviols y César Itier. Cusco: Centro de Estudios Regionales Andinos Bartolomé de las Casas.

1995 [ca. 1613] Relación de antigüedades de este reino del Perú. Edición, índice analítico y glosario de Carlos Araníbar. México: Fondo de Cultura Económica.

2019 [ca. 1613] Relación de Antigüedades deste Reyno del Pirú. Edición crítica de Jan Szemiński. Arequipa: Ediciones El Lector.

TAYLOR, Gerald (ed.)

1999 [¿1608?] Ritos y Tradiciones de Huarochirí. Lima: IFEA; BCRP; Universidad Ricardo Palma.

2007 [¿1598?] Dioses y hombres de Huarochirí. Narración quechua recogida por Francisco de Ávila. En: José María Arguedas (ed.). Lima: Universidad Antonio Ruiz de Montoya.

YupanQui, Titu Cusi

1992 [1570] Instrucción al licenciado Lope García de Castro. Estudio preliminar y edición por Liliana Regalado de Hurtado. Lima: PUCP.

\section{FuENTES SECUNDARIAS}

Adorno, Rolena

1982 (ed.) From oral to written expression: native andean chronicles of the early colonial period. Syracuse: Maxwell School of Citizenship and Public Affairs.

1992 Cronista y príncipe. La obra de Felipe Guaman Poma de Ayala. Lima: Pontificia Universidad Católica del Perú.

2000 Guaman Poma. Writing and resistance in colonial Peru. Austin: University of Texas Press; Institute of Latin American Studies.

Alaperrine-Bouyer, Monique

2007 La educación de las élites indígenas en el Perú colonial. Lima: IFEA; Instituto Riva Agüero; Instituto de Estudios Peruanos.

Calvet, Louis-Jean

2013 Historia de la escritura. De Mesopotamia hasta nuestros días. Barcelona: Austral. 
Cerrón-Palomino, Rodolfo

1987 Lingüistica quechua. Cusco: Centro de Estudios Regionales Bartolomé de Las Casas.

2010 «El contacto inicial quechua-castellano: la conquista del Perú con dos palabras». Lexis, vol. XXXIV, núm. 2, pp. 369-381.

2013 Tras las huellas del Inca Garcilaso: el lenguaje como hermenéutica en la comprensión del pasado. Boston: Latinoamericana Libros.

Chang-Rodríguez, Raquel

2005 La palabra y la pluma en «Primer nueva corónica y buen gobierno». Lima: Pontificia Universidad Católica del Perú.

Chang-Rodríguez, Raquel (ed.)

2010 Entre la espada y la pluma. El Inca Garcilaso y sus Comentarios Reales. Lima: Pontificia Universidad Católica del Perú.

Cook, Noble David

2010 La catástrofe demográfica andina. Perú 1520-1620. Lima: Pontificia Universidad Católica del Perú.

DERrida, Jacques

1998 [1967] De la gramatología. México: Siglo XXI.

DuEÑAS, Alcira

2010 Indians and Mestizos in the «Lettered City». Reshaping justice, social hierarchy, and political culture in colonial Peru. Colorado: University Press of Colorado.

DuRAND, Gilbert

1993 De la mitocrítica al mitoanálisis. Figuras míticas y aspectos de la obra. Barcelona: Editorial Anthropos.

Duviols, Pierre

1977 La destrucción de las religiones andinas (conquista y colonia). México: Universidad Nacional Autónoma de México.

Eliade, Mircea

1996 Mito y realidad. Colombia: Labor. 
Escobar, Alberto, José Matos Mar y Giorgio Alberti (eds.).

1975 Perú, ¿̇aaís bilingüe? Lima: Instituto de Estudios Peruanos.

Estenssoro, Juan Carlos

2003 Del paganismo a la santidad. La incorporación de los indios del Perú al catolicísimo. 1532-1750. Lima: Pontificia Universidad Católica del Perú; IFEA.

GonZÁLez VigiL, Ricardo

2016 Inca Garcilaso de la Vega. Comentarios reales y otros textos. Lima: Penguin Books.

GruZINSKI, Serge

2013 [1995] La colonización del imaginario. Sociedades indigenas y occidentalización en el México Español. S. XVI y XVII. México: Fondo de Cultura Económica.

Guibovich, Pedro

1990-1992 «Lectura y difusión de la obra del Inca Garcilaso de la Vega en el virreinato peruano (siglos XVII y XVIII). El caso de los Comentarios Reales». Revista Histórica, Lima, núm. 37, pp. 103-120.

HaLBWACHS, Maurice

2004a [1968] La memoria colectiva. Zaragoza: Prensas Universitarias de Zaragoza. 2004b [1994] Los marcos sociales de la memoria. Barcelona: Anthropos.

Hampe Martínez, Teodoro

1996 Bibliotecas privadas en el mundo colonial. La difusión de libros e ideas en el virreinato del Perú (siglos XVI-XVII). Madrid: IberoamericanaVervuert.

Hemming, John

2004 [1970] La conquista de los incas. México: Fondo de Cultura Económica.

HERnÁNDEZ, Max

1993 Memoria del bien perdido; conflicto, identidad, nostalgia en el Inca Garcilaso de la Vega. Lima: Instituto de Estudios Peruanos. 
Herrera Villagra, Alejandro

2016 Escritura andina colonial. La construcción de una memoria indígena en los Andes, siglos XVI y XVII. Tesis de doctorado. Santiago de Chile: Universidad de Chile.

2017 «En torno a la lengua quechua y su evolución diacrónica en el contexto andino letrado colonial. Siglos XVI al XVIII». Manuscrito inédito.

2018 «Inca Garcilaso de la Vega: las dificultades del lenguaje en la escritura de la historia de los Andes». En: David Franco Córdova y Antonio Chang Huayanca (comps.). Inca Garcilaso: 400 años. Lima: Universidad Ricardo Palma, pp. 247-260.

2019 «Titu Cusi Yupanqui: diálogo, comunicación y traducción en la redacción de epístolas entre la Mascapaicha quechua y la Corona española, Vilcabamba, 1560-1570». En: Roberto Ojeda Escalante y Alejandro Herrera Villagra (comps.). Yuyay Taqe - Los incas en su tiempo y en el nuestro. Cusco: Universidad Andina del Cusco, pp. 69-117.

IbARRa Grasso, Dick

1953 La escritura indígena andina. La Paz: Biblioteca Paceña.

ITIER, Cesar

2015 «"Quechua" y el sistema inca de denominación de lenguas». Mélanges de la Casa de Velázquez: Nouvelle serie, vol. 45, núm. 1, pp. 37-56.

Kaulicke, Peter

2016 [2001] Memoria y muerte en el Perú antiguo. Lima: Pontificia Universidad Católica del Perú.

LACAN, Jacques

1982 «Le symbolique, l'imaginaire et le reel (1953)». Bulletin de L'Association freudienne, núm. 1, pp. 4-13.

Lamana, Gonzalo

2019 How «Indians» think. Colonial indigenous intellectuals and the question of critical race theory. Tucson: University of Arizona Press. 
LIENHARD, Martin

2016 «Textos indígenas». En: Joanne Pillsbury (ed). Fuentes documentales para los estudios andinos, 1530-1900. Tomo I. Lima: Pontificia Universidad Católica del Perú; National Gallery of Art; Center for Advanced Study in the Visual Arts, pp. 167-195.

LÓpez-Baralt, Mercedes

1993 Guaman Poma. Autor y artista. Lima: Pontificia Universidad Católica del Perú.

LOTMAN, Iuri M.

1996 La semiosfera I. Semiótica de la cultura y del texto. Madrid: Cátedra.

MacCormack, Sabine

2016 [1991] Religión en los Andes. Visiones e imaginación en el Perú colonial. Arequipa: Ediciones El Lector.

Mazzotti, José Antonio

2016 Encontrando un inca. Ensayos escogidos sobre el Inca Garcilaso de la Vega. Salem; Lima; Nueva York: Axiara Editions; Academia Norteamericana de la Lengua Española (ANLE).

Mazzotтi, José Antonio (ed.)

2010 Renacimiento mestizo: los 400 años de los Comentarios Reales. Madrid: Iberoamericana-Vervuert.

MerLuzzi, Manfredi

2014 Gobernando los Andes. Francisco de Toledo virrey del Perú (1569-1581). Lima: PUCP; Roma Tre; Università Degli Studi.

Murra, John V.

2002 «Las etnocategorías de un khipu estatal». En: John V. Murra. El mundo andino. Población, medio ambiente y economía. Lima: Pontificia Universidad Católica del Perú, pp. 248-260.

Navarro Gala, Rosario

2015 Elprimer notario indígena y su libro de protocolo (Cuzco, siglo XVI): cuestiones filológicas, discursivas y de contacto de lenguas. Madrid; Frankfurt: Iberoamericana-Vervuert. 
Nora, Pierre

2009 [1984] Pierre Nora y Les lieux de mémoire. Santiago de Chile: LOM; Trilce.

ONG, Walter J.

2004 Oralidad y escritura. Tecnologías de las palabras. México: Fondo de Cultura Económica.

Ossio, Juan

2008 En busca del orden perdido. La idea de la Historia en Felipe Guaman Poma de Ayala. Lima: Pontificia Universidad Católica del Perú.

PARKER, Gary

2013 Trabajos de lingüistica histórica quechua. En: Rodolfo Cerrón Palomino (ed.). Lima: Pontificia Universidad Católica del Perú.

Pärsinnen, Martti y Jukka Kiviharju (eds.)

2004 Textos andinos. Corpus de textos khipu incaicos y coloniales. Madrid: Instituto Iberoamericano de Finlandia; Universidad Complutense de Madrid.

Porras Barrenechea, Raúl

1986 Los cronistas del Perú (1528-1650). Edición, prólogo y notas de Franklin Pease G. Y., bibliografía de Félix Álvarez Brun y Graciela Sánchez Cerro, revisado por Oswaldo Holguín Callo. Lima: Banco de Crédito del Perú.

Ramos, Gabriela y Yanna Yannakakis (eds.)

2014 «Introduction». En: Gabriela Ramos y YannaYannakakis (eds). Indigenous intellectuals: knowledge, power, and colonial culture in Mexico and the Andes. Durham \& London: Duke University Press, pp. 1-17.

Ricoeur, Paul

2008 [2000] La memoria, la historia, el olvido. México: Fondo de Cultura Económica.

SiLVERMAN, Gail

2014 Los signos del imperio. La escritura pictográfica de los incas. Tomo 1. Lima: Biblioteca Abraham Valdelomar. 
Torero, Alfredo

2005 Idiomas de los Andes. Lingüistica e historia. Lima: Editorial Horizonte. 2007 [1974] El quechua y la historia social andina. Lima: Fondo Editorial del Pedagógico San Marcos.

Trevor-Roper, Hugh

2009 La crisis del siglo XVII. Religión, reforma y cambio social. Buenos Aires: Katz.

URTON, Gary

2016 «El quipu. Una historia de los escritos y estudios sobre los registros en cordeles anudados, incaicos y coloniales». En: Joanne Pillsbury (ed). Fuentes documentales para los estudios andinos, 15301900. Tomo 1. Lima: PUCP; National Gallery of Art; Center for Advanced Study in the Visual Arts, pp. 133-166.

2017 La historia inka en nudos. Leyendo khipus como fuentes primarias. Trujillo: Universidad Nacional de Trujillo.

2019 «Algunas reflexiones sobre la escritura de la historia del Tahuantinsuyo a partir de fuentes primarias (quipus)». Allpanchis, núm. 83-84, pp. 19-38.

VARgas UgarTe, Rubén

1951-1954 Concilios Limenses (1551-1772). 3 vols. Lima: Talleres Gráficos de la Tipografía Peruana.

Yates, Frances A.

2006 [1966] El arte de la memoria. Madrid. Siruela.

Fecha de recepción: 27 de marzo de 2020.

Fecha de aceptación: 15 de junio de 2020.

Fecha de publicación: 1 de diciembre de 2020. 